\title{
Factors associated with dental caries in the primary dentition of children with cerebral palsy
}

\section{Luana Leal Roberto(a) Mariana Gomes Machado(a) Vera Lúcia Silva Resende ${ }^{(b)}$ Lia Silva Castilho(b) Mauro Henrique Nogueira Guimarães de Abreu ${ }^{(a)}$}

(a) Department of Community and Preventive Dentistry, School of Dentistry, Univ Federal de Minas Gerais - UFMG, Belo Horizonte, MG, Brazil.

(b) Department of Operative Dentistry, School of Dentistry, Univ Federal de Minas Gerais UFMG, Belo Horizonte, MG, Brazil.

Declaration of Interests: The authors certify that they have no commercial or associative interest that represents a conflict of interest in connection with the manuscript.

Corresponding Author:

Mauro Henrique Nogueira Guimarães de Abreu

E-mail: maurohenriqueabreu@ig.com.br

Submitted: Mar 12, 2012

Accepted for publication: Jul 05, 2012

Last revision: Jul 13, 2012

\begin{abstract}
The aim of this study was to investigate factors associated with caries experience in the primary dentition of one- to five-year-old children with cerebral palsy. A total of 266 dental records were examined, and caries experience was measured by $\mathrm{dmft}$. The following variables were also analyzed: gender, oral hygiene, history of gastroesophageal reflux, use of medications for gastroesophageal reflux, gingival status, sugar intake and reports of polyuria, excessive thirst and xerostomia. For analysis purposes, the individuals were categorized as those with and without caries experience and subcategorized into the following age groups: one year; two to three years; and four to five years. After bivariate analysis, variables with a $\mathrm{p}$-value $<0.25$ were selected for incorporation into the Poisson regression models. Considering the limitations of the protocol, the level of oral hygiene perceived on the first appointment was the only factor associated with caries experience among two-to-fiveyear-old children with cerebral palsy.
\end{abstract}

Descriptors: Dental Caries; Epidemiology; Disabled Persons.

\section{Introduction}

Disease conditions of the oral cavity occur with greater frequency in individuals with special needs. ${ }^{1}$ Dental caries constitute a multifactor disease in which different biological, economic, cultural, environmental and social factors interact. ${ }^{2}$ The literature presents conflicting data on the prevalence of dental caries among individuals with disabilities, as these results cannot be generalized and tend to differ between countries. ${ }^{3}$ The results of various studies have been inconclusive as to whether children with cerebral palsy $(\mathrm{CP})$ have a higher caries rate than other children. ${ }^{3}$

While it is known that dental caries can be associated with systemic factors, ${ }^{2-4}$ the scientific literature does not address the relationship between such systemic factors and dental caries in the primary teeth of patients with CP. While CP patients may have comorbidities, ${ }^{3,5}$ the objective of this study was to investigate factors associated with caries experience in the primary dentition of one- to five-year-old children with cerebral palsy who were treated at a reference service for Patients with Special Needs, Belo Horizonte, MG, Brazil.

\section{Methodology}

The study was approved by the Human Research Ethics Committee 
of the Universidade Federal de Minas Gerais (process no. ETIC 219/03). A cross-sectional epidemiological study was carried out using information collected from dental charts that were obtained from a reference center for the rehabilitation of children with CP, which is affiliated with the aforementioned university and with the Mineira Rehabilitation Association.

A total of 266 charts from one- to five-year old children with CP, who were treated between January 1998 and December 2010, were examined. Data from outcomes and independent variables were simultaneously extracted from the patients' files by the same trained observer, without any necessary patient reexaminations. Although this study does not provide an exact measurement of intrarrater agreement, the observer consistently followed the daily routine employed in this center. A single professor supervised the diagnosis of dental caries and subsequent annotations on the charts. Examiners attended at least two hours of lecture and two hours of practical demonstrations before starting dental care. Caries experience was determined by the presence of cavities and restorations that were recorded when the patients visited the school for the first time. The $m$ component of the decayed, missing and filled teeth index ( $\mathrm{dmft}$ ) was quantified only when a tooth was indicated for extraction due to dental caries. Missing teeth were not included in the analysis, as it was impossible to determine whether the teeth were lost due to extraction or physiological exfoliation. No teeth were lost due to agenesis. Radiographic exams were not performed due to the patients' high degree of spasticity, involuntary movements and cognitive impairment.

For analysis purposes, the individuals were categorized as those with or without caries experience. The following variables were also analyzed:

- gender,

- oral hygiene,

- history of gastroesophageal reflux,

- use of medications for gastroesophageal reflux,

- gingival status,

- sugar intake and

- reports of

- polyuria,
- excessive thirst and

- xerostomia.

Oral hygiene was recorded as "good", "fair" or "poor." "Sugar intake was assessed using the sucrose intake index. ${ }^{7}$ Gingival status was determined by evaluating the presence or absence of inflammatory gingival alterations. ${ }^{8}$ Respiration was classified as either mouth or nose breathing. All other independent variables were assessed based on their presence or absence.

The bivariate (Pearson's chi-squared test and Fisher's exact test) and multivariate (Poisson Regression models with robust variance) statistical analyses were performed by subcategorizing the sample into statistically similar age groups relative to caries experience $(\mathrm{p}>0.05)$ :

- one year,

- two to three years, and

- four to five years.

Stratification by age has been used in epidemiological studies on dental caries because of the strong influence of age on the manifestations of the disease. $^{9}$

Central tendency and variability measures were calculated for each component of the $\mathrm{dmft}$ for each of the age groups. Bivariate analysis was performed to test the influence of the independent variables on caries experience (dependent variable). This variable was dichotomized as the absence or presence of caries in the primary dentition $(\mathrm{dmft}=0$ and $\mathrm{dmft}>0)$. Poisson regression models were constructed, with the calculation of prevalence ratios (PR) and 95\% confidence intervals $(95 \% \mathrm{CI})$ for covariables with a $\mathrm{p}$-value $<0.25$ in the bivariate analysis. Variables with a p-value $<0.05$ remained in the final models.

\section{Results}

The sample, subdivided into age groups, had the following distribution:

- 73 one-year-olds (27.4\%),

- 115 two- to three-year-olds $(43.2 \%)$ and

- 78 four- to five-year-olds ( $\mathrm{n}=78,29.3 \%)$.

The descriptive analysis is presented in Table 
Table 1 - Distribution of dental caries among Brazilian patients aged 1 to 5 years, 1998-2010.

\begin{tabular}{|c|c|c|c|}
\hline & 1 year old & $\begin{array}{c}2 \text { to } 3 \\
\text { years old }\end{array}$ & $\begin{array}{c}4 \text { to } 5 \\
\text { years old }\end{array}$ \\
\hline \multicolumn{4}{|c|}{$d$} \\
\hline mean (SD) & $0.18( \pm 1.08)$ & $0.78( \pm 1.69)$ & $1.58( \pm 3.0)$ \\
\hline median & 0 & 0 & 0 \\
\hline $\min .-\max$ & $0-9$ & $0-10$ & $0-16$ \\
\hline \multicolumn{4}{|c|}{$\mathrm{m}$} \\
\hline mean (SD) & 0 & $0.03( \pm 0.2)$ & $0.08( \pm 0.35)$ \\
\hline median & 0 & 0 & 0 \\
\hline $\min .-\max$ & 0 & $0-2$ & $0-2$ \\
\hline \multicolumn{4}{|c|}{$f$} \\
\hline mean (SD) & 0 & $0.04( \pm 0.29)$ & $0.29( \pm 1.1)$ \\
\hline median & 0 & 0 & 0 \\
\hline $\min .-\max$ & 0 & $0-3$ & $0-8$ \\
\hline \multicolumn{4}{|c|}{$\mathrm{dmft}$} \\
\hline mean $(\mathrm{SD})$ & $0.18( \pm 1.09)$ & $0.85( \pm 1.77)$ & $1.95( \pm 3.25)$ \\
\hline median & 0 & 0 & 0 \\
\hline $\min .-\max$ & $0-9$ & $0-10$ & 0-17 \\
\hline
\end{tabular}

1. Sixty-eight $(93.15 \%)$ of the one-year-olds, 84 $(73.0 \%)$ of the two- to three-year-olds and 44 $(56.4 \%)$ of the four- to five-year-olds were cariesfree.

Table 1 describes the $\mathrm{dmft}$ index. The $\mathrm{dmft}$ in older groups was significantly higher than that of the other groups, and this difference was especially dominant in the $\mathrm{d}$ component.

Bivariate and multivariate analyses are presented in Tables 2 and 3. Both analyses illustrate the association of oral hygiene with caries experience in the two- to three-year-old and four- to five-year-old groups.

\section{Discussion}

This study focused on young patients with CP because the scientific literature does not often address the local and systemic factors associated with dental caries in these patients' primary teeth. Additionally, the statistical analysis of dental caries in different age groups is challenging. When age is included in multivariate models, this variable is almost always associated with dental caries. Moreover, the number of erupted teeth is quite different among age groups, so the inclusion of age as a variable in multivariate models for dental caries may not give consistent estimates of prevalence ratios. For this reason, we controlled for this influence of age on dental caries by stratifying the analysis by age. ${ }^{9}$ On the other hand, our methodological option did not allow for the adjustment of the multiple models by age. While the dental caries experience is quite different among age groups, decayed teeth comprised more than $80 \%$ of the caries experience in all age groups. Considering the historical lack of dental assistance for patients with special needs, this proportion of non-treated dental caries can be expected in CP patients. ${ }^{3}$ There were no significant differences in the proportions of each independent variable measured in all age groups, except for the use of medications for reflux ( $\mathrm{p}=0.007$, data not shown).

According to the most recent national oral health survey in Brazil, $46.6 \%$ of Brazilian five-yearold children are caries free. This figure increases to $51.9 \%$ in the southeastern region and exhibits a slight reduction in the city of Belo Horizonte $(45.7 \%) .{ }^{10}$ Although the results of various studies have not conclusively established that children with $\mathrm{CP}$ have a higher caries rate than other children, ${ }^{3}$ in the present study, the patients in the four- to fiveyear-old age group had a lower $\mathrm{dmft}$ index than the overall mean reported for Brazilian children. The children evaluated in our study were not representative of all children with CP, but only of those who look for treatment in a reference center. These children may possess better oral health due to enhanced parental attention and/or fewer difficulties in controlling oral conditions.

The multifactorial etiology of dental caries, which is the result of the interaction of various biological, economic, cultural, environmental and social factors, is well established. ${ }^{2}$ Social variables and the use of fluoride were not evaluated in our study. For Brazilian children, oral hygiene habits and the use of fluoride toothpaste are intrinsically related; thus, the use of fluoride may have an effect on caries experience. In the present study, oral hygiene was the only variable that displayed a statistically significant association with caries experience. While 
Table 2 - Association of independent variables with caries experience in the primary dentition, according to age group, in Brazilian patients aged 1 to 5 years, $1998-2010$.

\begin{tabular}{|c|c|c|c|c|c|c|c|c|c|}
\hline & \multicolumn{3}{|c|}{1 year old } & \multicolumn{3}{|c|}{2 to 3 years old } & \multicolumn{3}{|c|}{4 to 5 years old } \\
\hline & $\mathrm{dmft}=0$ & $\mathrm{dmft} \geq 1$ & $p$ & $\mathrm{dmft}=0$ & $\mathrm{dmft} \geq 1$ & $p$ & $\mathrm{dmft}=0$ & $\mathrm{dmft} \geq 1$ & $p$ \\
\hline \multicolumn{10}{|c|}{ Gender } \\
\hline Male & 39 & 3 & \multirow{2}{*}{$0.636 *$} & 46 & 17 & \multirow{2}{*}{$0.444 \dagger$} & 27 & 18 & \multirow{2}{*}{$0.303 t$} \\
\hline Female & 29 & 1 & & 38 & 12 & & 17 & 16 & \\
\hline \multicolumn{10}{|c|}{ Reflux } \\
\hline Present & 13 & 0 & \multirow{2}{*}{$0.442^{*}$} & 6 & 4 & \multirow{2}{*}{$0.216^{*}$} & 6 & 4 & \multirow{2}{*}{$0.543^{*}$} \\
\hline Absent & 55 & 4 & & 78 & 24 & & 38 & 30 & \\
\hline \multicolumn{10}{|c|}{ Oral hygiene } \\
\hline Good & 58 & 1 & \multirow{3}{*}{$0.202^{*}$} & 71 & 16 & \multirow{3}{*}{$<0.001^{*}$} & 36 & 18 & \multirow{3}{*}{$0.003^{*}$} \\
\hline Fair & 5 & 1 & & 8 & 7 & & 4 & 6 & \\
\hline Poor & 1 & 0 & & 0 & 5 & & 0 & 6 & \\
\hline \multicolumn{10}{|c|}{ Medication for reflux } \\
\hline Absent & 57 & 4 & \multirow{2}{*}{$0.507^{*}$} & 81 & 27 & \multirow{2}{*}{$0.381^{*}$} & 40 & 31 & \multirow{2}{*}{$0.625^{*}$} \\
\hline Present & 11 & 0 & & 3 & 2 & & 3 & 2 & \\
\hline \multicolumn{10}{|c|}{ Xerostomia } \\
\hline Present & 10 & 1 & \multirow{2}{*}{$0.504^{*}$} & 11 & 8 & \multirow{2}{*}{$0.076 \dagger$} & 4 & 3 & \multirow{2}{*}{$0.633^{*}$} \\
\hline Absent & 56 & 3 & & 71 & 21 & & 40 & 29 & \\
\hline \multicolumn{10}{|c|}{ Excessive thirst } \\
\hline Present & 8 & 1 & \multirow{2}{*}{$0.431^{*}$} & 11 & 5 & \multirow{2}{*}{$0.409+$} & 5 & 6 & \multirow{2}{*}{$0.515 \dagger$} \\
\hline Absent & 58 & 3 & & 71 & 24 & & 39 & 27 & \\
\hline \multicolumn{10}{|c|}{ Polyuria } \\
\hline Present & 17 & 1 & & 69 & 21 & & 6 & 6 & \\
\hline Absent & 49 & 3 & 0.124 & 13 & 7 & $0.204 \uparrow$ & 35 & 26 & $0.436 \dagger$ \\
\hline & & & & Gingiva & problems & & & & \\
\hline Present & 5 & 1 & 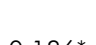 & 13 & 4 & 0 & 3 & 7 & $000<$ \\
\hline Absent & 55 & 1 & 0.100 & 65 & 21 & 0.005 & 36 & 25 & $0.086^{\circ}$ \\
\hline & & & & Suga & intake & & & & \\
\hline$\leq 7$ & 13 & 0 & $075 \%$ & 22 & 8 & נות ח & 11 & 7 & 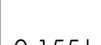 \\
\hline$>7$ & 37 & 1 & 0.145 & 29 & 16 & 0.2411 & 12 & 17 & | \\
\hline & & & & Mouth & oreathing & & & & \\
\hline Present & & & & 39 & 11 & , & 28 & 16 & 0 \\
\hline Absent & & & & 45 & 18 & .2001 & 16 & 16 & 0.1701 \\
\hline
\end{tabular}

*Fisher's exact test; †Pearson's chi-squared test; there are missing data for some variables. diet is an important variable in the etiology of this condition, oral hygiene is the main predisposing factor in the development of dental caries-a fact that is widely discussed in the literature. The disorganization of biofilms, accompanied by the application of topical fluoride, remains one of the most effective individual procedures for the control of dental caries. ${ }^{4,11}$ The data from the present study confirm this statement, as the model revealed a biological gradient for the oral hygiene variable. ${ }^{12}$

The association between the level of oral hygiene and dental caries in patients with special needs is widely discussed in the literature. Patients with CP may exhibit unsatisfactory oral hygiene, as they may not possess the level of motor skills necessary for the thorough cleaning of the oral cavity. ${ }^{13}$ In addition to 
Table 3 - Multivariate analysis of oral hygiene (independent variable) associated with caries experience in the primary dentition, according to age group, in Brazilian patients aged 1 to 5 years, $1998-2010$.

\begin{tabular}{c|c|r}
\hline Variable & PR (95\% CI) & \multicolumn{1}{c}{$P$} \\
\hline \multicolumn{3}{c|}{2 to 3 years old } \\
\hline Good oral hygiene & $0.18(0.12-0.29)$ & $<0.001$ \\
\hline Fair oral hygiene & $0.47(0.27-0.80)$ & 0.006 \\
\hline Poor oral hygiene (reference) & 1 & \\
\hline \multicolumn{3}{c}{4 to 5 years old } \\
\hline Good oral hygiene & $0.33(0.23-0.49)$ & $<0.001$ \\
\hline Fair oral hygiene & $0.60(0.36-0.99)$ & 0.048 \\
\hline Poor oral hygiene (reference) & 1 & \\
\hline
\end{tabular}

these limitations in personal skills, caregivers of CP patients also experience difficulties in maintaining satisfactory oral hygiene in these children. ${ }^{14}$ Nonetheless, the assistance and support of others is fundamental to the maintenance of oral health, ${ }^{1}$ which is supported by the fact that a greater caries experience is observed in individuals with no oral hygiene assistance..$^{15}$ Along with physical limitations, individuals with CP may also exhibit some degree of cognitive impairment, which further hinders the adoption of adequate oral hygiene practices. ${ }^{13}$ Such patients are often unable to follow instructions or understand the importance of maintaining satisfactory oral hygiene. ${ }^{16}$

In the present study, sugar intake was not shown to be significantly associated with caries experience, which disagrees with most findings in the literature. ${ }^{15}$ However, a recent systematic review suggested that the relationship between sugar consumption and caries is presently less substantial than it was in the past. ${ }^{17}$

One study ${ }^{16}$ showed that female gender is a predisposing factor for dental caries, especially in the permanent dentition of disabled individuals. However, in the present study, no significant association was found between caries experience and gender. The diversity of individuals ${ }^{16}$ could explain this difference in the results. Furthermore, higher caries prevalence among females is often explained by factors $^{18}$ that are not relevant in our group of patients.

Mouth breathing has frequently been reported in patients with CP. ${ }^{19}$ This trait predisposes an individual to an increased number of bacteria in the oral cavity, ${ }^{20}$ augmenting the patient's susceptibility to dental caries. ${ }^{21}$ However, the present study did not corroborate this notion.

In patients with asthma, xerostomia has been reported to be associated with a greater incidence of dental caries and gingival bleeding. ${ }^{8}$ Xerostomia is also a frequent clinical finding in patients with $\mathrm{CP}$. This reduction in salivary flow may be a side effect of medications, or it may indicate a possible autonomic disorder, hypohydration and/or salivary gland deficiency in individuals with spastic CP. ${ }^{22}$ Despite these considerations, in this study, a history of xerostomia was not associated with caries. The reason for this observation could be that we did not conduct specific tests to evaluate salivary flow, as the applicability of these tests in patients with CP is limited. Additionally, diabetic patients often report excessive thirst and polyuria, and the literature supports an association between dental caries and poorly controlled diabetes. ${ }^{23}$ However, this association is not always observed, as was the case in the present study. ${ }^{24}$

Gastroesophageal reflux (GER) is another common characteristic in this group of patients, and this condition has been investigated as a potential causal agent of dental caries. Tooth erosion is an oral condition that has been associated ${ }^{25}$ with or has indicated $^{26}$ GER disease. Few studies have linked dental caries to GER, and there is no consensus on whether patients with this condition have a greater or lesser caries experience when compared to healthy individuals. $^{25,27}$ Some studies demonstrate that GER is associated with the development of dental caries, ${ }^{28}$ whereas other studies report that this disorder plays a protective role against dental caries. ${ }^{27}$ Some association with dental caries should be expected. Because CP patients' motor and cognitive impairments often result in difficulty swallowing, ${ }^{29}$ this behavior, combined with GER, may contribute to an increase in the prevalence of dental erosion; the acidic material from the stomach would take longer to be swallowed or spat out, remaining in contact with dental tissues for extended periods of time. As in previous papers ${ }^{27}$ the present study found no association be- 
tween reflux and dental caries, indicating that the methodology employed was likely inadequate for the investigation of this issue.

The limitations of this study should be addressed. The data were obtained from dental charts, which were initially intended for oral health care, a purpose that is not related to the present study. Moreover, the cross-sectional study design did not allow for the establishment of causal relationships between the variables and caries experience. In addition, as in previous studies, the study participants were from a rehabilitation institution, and the results are therefore not necessarily representative of the general population. ${ }^{1}$

The Brazilian and international literature does not thoroughly address factors associated with dental caries in children with CP. The results of the present study may guide the conduct of dentists who work with this population group and may help establish a differentiated oral healthcare protocol for patients who exhibit inadequate oral hygiene at the first dental appointment. The determination of the degree of oral hygiene is essential to the establish-

\section{References}

1. Pezzementi ML, Fisher MA. Oral health status of people with intellectual disabilities in the southeastern United States. J Am Dent Assoc. 2005 Jul;136(7):903-12.

2. Holst D. Causes and prevention of dental caries: a perspective on cases and incidence. Oral Health Prev Dent. $2005 \mathrm{Jan} ; 3(1): 9-14$.

3. Dougherty NJ. A review of cerebral palsy for the oral health professional. Dent Clin North Am. 2009 Apr;53(2):329-38.

4. Fejerskov O. Changing paradigms in concepts on dental caries: consequences for oral health care. Caries Res. 2004 May;38(3):182-91.

5. Guaré RO, Ferreira MC, Leite MF, Rodrigues JA, Lussi A, Santos MT. Dental erosion and salivary flow rate in cerebral palsy individuals with gastroesophageal reflux. J Oral Pathol Med. 2012 May;41(5):367-71.

6. Greene JC, Vermillion JR. The simplified oral hygiene index. J Am Dent Assoc. 1964 Jan;68:7-13.

7. Auad SM, Pordeus IA. Nutrição e sua influência nos processos de odontogênese, erupção e desenvolvimento da cárie dentária. Rev CROMG. 1999;5(3):151-5.

8. Stensson M, Wendt L-K, Koch G, Oldaeus G, Lingström $\mathrm{P}$, Birkhed D. Caries prevalence, caries-related factors and ment of caries control strategies during the planning and execution of treatment. Moreover, the present findings may assist in the development of public policies designed to broaden the network of dental care to this group of patients, especially through the adoption of preventive measures and the promotion of healthy habits, especially oral hygiene habits. The findings reported herein also underscore the need for the effective training of caregivers, as patients with CP depend upon others for the maintenance of their oral health.

\section{Conclusion}

The level of oral hygiene observed at the first dental appointment is associated with caries experience in most age groups of children with cerebral palsy.

\section{Acknowledgments}

We would like to thank The Minas Gerais State Research Foundation (FAPEMIG) and Pró-reitoria de Pesquisa - UFMG for the financial assistance.

plaque $\mathrm{pH}$ in adolescents with long-term asthma. Caries Res. 2010;44(6):540-6.

9. Abreu MHNG, Pordeus IA, Modena CM. Cárie dentária entre escolares do meio rural de Itaúna (MG), Brasil. Rev Panam Salud Publica. 2004 Nov;16(5):334-44.

10. Brasil. Ministério da Saúde. Secretaria de Atenção à Saúde, Secretaria de Vigilância em Saúde. Departamento de Atenção Básica. Coordenação Nacional de Saúde Bucal. SB Brasil 2010: pesquisa nacional de saúde bucal 2010. Brasília (DF): Ministério da Saúde; 2011. [citado 10 nov. 2011]. Disponível em: http://189.28.128.100/dab/docs/geral/projeto_sb2010_relatorio_final.pdf.

11. Maltz M, Jardim JJ, Alves LS. Health promotion and dental caries. Braz Oral Res. 2010;24 Suppl 1:18-25.

12. Grimes D, Schulz KF. Bias and causal associations in observational research. Lancet. 2002 Jan;359(9302):248-52.

13. Rao D, Amitha H, Munshi AK. Oral hygiene status of disabled children and adolescents attending special schools of South Canara, India. Hong Kong Dent J. 2005 Dec;2(2):107-13.

14. Camargo MAF, Antunes JLF. Untreated dental caries in children with cerebral palsy in the Brazilian context. Int J Paediatr Dent. 2008 Mar;18(2):131-8. 
15. Pradhan A, Slade GD, Spencer AJ. Factors influencing caries experience among adults with physical and intellectual disabilities. Community Dent Oral Epidemiol. 2009 Apr;37(2):14354.

16. Altun C, Guven G, Akgun OM, Akkurt MD, Basak F, Akbulut E. Oral health status of disabled individuals attending special schools. Eur J Dent. 2010 Oct;4(4):361-6.

17. Burt BA, Pai S. Sugar consumption and caries risk: a systematic review. J Dent Educ. 2001 Oct;65(10):1017-23.

18. Lukacs JR, Largaespada LL. Explaining sex differences in dental caries prevalence: saliva, hormones, and "life-history" etiologies. Am J Hum Biol. 2006 Jul-Aug;18(4):540-55.

19. Santos MTBR, Masiero D, Novo NF, Simionato MRL. Oral Conditions in children with cerebral palsy. J Dent Child (Chic). 2003 Jan;70(1):40-6.

20. Weiler RM, Fisberg M, Barroso AS, Nicolau J, Simi R, Siqueira Jr WL. A study of the influence of mouth-breathing in some parameters of unstimulated and stimulated whole saliva of adolescents. Int J Pediatr Otorhinolaryngol. 2006 May;70(5):799-805.

21. Nascimento Filho E, Mayer MP, Pontes P, Pignatari AC, Weckx LL. Caries prevalence, levels of mutans streptococci, and gingival and plaque indices in 3.0- to 5.0-year-old mouth breathing children. Caries Res. 2004 Nov;38(6):572-5.

22. Santos MT, Guaré R, Leite M, Ferreira MC, Nicolau J. Does the neuromotor abnormality type affect the salivary param- eters in individuals with cerebral palsy?. J Oral Pathol Med. 2010 Nov;39(10):770-4.

23. Stojanović N, Krunić J, Cicmil S, Vukotić O. [Oral health status in patients with diabetes mellitus type 2 in relation to metabolic control of the disease]. Srp Arh Celok Lek. 2010 Jul;138(7-8):420-4. Servian.

24. Jawed M, Shahid SM, Qader SA, Azhar A. Dental caries in diabetes mellitus: role of salivary flow rate and minerals. J Diabetes Complications. 2011 May;25(3):183-6.

25. Pace F, Pallotta S, Tonini M, Vakil N, Bianchi Porro G. Systematic review: gastro-oesophageal reflux disease and dental lesions. Aliment Pharmacol Ther. 2008 Jun;27(12):1179-86.

26. Muñoz JV, Herreros B, Sanchiz V, Amoros C, Hernandez $\mathrm{V}$, Pascual I, et al. Dental and periodontal lesions in patients with gastro-oesophageal reflux disease. Dig Liver Dis. 2003 Jul;35(7):461-7.

27. Corrêa MCCSF, Lerco MM, Henry MACA. Estudo de alterações na cavidade oral em pacientes com doença do gastroesophageal reflux. Arq Gastroenterol. 2008 Apr-Jun;45(2):132-6.

28. Linnett V, Seow WK, Connor F, Shetherd R. Oral health of children with gastro-esophageal reflux disease: a controlled study. Aust Dent J. 2002 Jun;47(2):156-62.

29. Idaira Y, Nomura Y, Tamaki Y, Katsumura S, Kodama S, Kurata K, et al. Factors affecting the oral condition of patients with severe motor and intellectual disabilities. Oral Dis. 2008 Jul;14(5):435-9. 